\title{
Assimilation of SMOS soil moisture into a distributed hydrological model and impacts on the water cycle variables over the Ouémé catchment in Benin
}

\author{
Delphine J. Leroux ${ }^{1,2}$, Thierry Pellarin ${ }^{3,4}$, Théo Vischel ${ }^{3}$, Jean-Martial Cohard ${ }^{3}$, Tania Gascon ${ }^{3}$, François Gibon ${ }^{3}$, \\ Arnaud Mialon ${ }^{2}$, Sylvie Galle ${ }^{3,5}$, Christophe Peugeot ${ }^{6}$, and Luc Seguis ${ }^{6}$ \\ ${ }^{1}$ CNES, LTHE, Laboratoire d'Étude des Transferts en Hydrologie et Environnement, Grenoble, France \\ ${ }^{2}$ CNRS, CESBIO, Centre d'Etudes Spatiales de la Biosphère, Toulouse, France \\ ${ }^{3}$ University Grenoble Alpes, LTHE, Grenoble, France \\ ${ }^{4}$ CNRS, LTHE, Grenoble, France \\ ${ }^{5}$ IRD, LTHE, Grenoble, France \\ ${ }^{6}$ IRD, HydroSciences, Montpellier, France
}

Correspondence to: Delphine J. Leroux (delphine.j.leroux@gmail.com)

Received: 21 December 2015 - Published in Hydrol. Earth Syst. Sci. Discuss.: 19 January 2016

Revised: 9 May 2016 - Accepted: 16 June 2016 - Published: 14 July 2016

\begin{abstract}
Precipitation forcing is usually the main source of uncertainty in hydrology. It is of crucial importance to use accurate forcing in order to obtain a good distribution of the water throughout the basin. For real-time applications, satellite observations allow quasi-real-time precipitation monitoring like the products PERSIANN (Precipitation Estimation from Remotely Sensed Information using Artificial Neural Networks, TRMM (Tropical Rainfall Measuring Mission) or CMORPH (CPC (Climate Prediction Center) MORPHing). However, especially in West Africa, these precipitation satellite products are highly inaccurate and the water amount can vary by a factor of 2 . A post-adjusted version of these products exists but is available with a 2 to 3 month delay, which is not suitable for real-time hydrologic applications. The purpose of this work is to show the possible synergy between quasi-real-time satellite precipitation and soil moisture by assimilating the latter into a hydrological model. Soil Moisture Ocean Salinity (SMOS) soil moisture is assimilated into the Distributed Hydrology Soil Vegetation Model (DHSVM) model. By adjusting the soil water content, water table depth and streamflow simulations are much improved compared to real-time precipitation without assimilation: soil moisture bias is decreased even at deeper soil layers, correlation of the water table depth is improved from $0.09-0.70$ to 0.82 0.87 , and the Nash coefficients of the streamflow go from negative to positive. Overall, the statistics tend to get closer
\end{abstract}

to those from the reanalyzed precipitation. Soil moisture assimilation represents a fair alternative to reanalyzed rainfall products, which can take several months before being available, which could lead to a better management of available water resources and extreme events.

\section{Introduction}

Surface soil moisture, as well as soil properties and precipitation intensity, is involved in the partitioning of rainfall into surface runoff and infiltration (water cycle), and also in the partitioning of the incoming solar and atmospheric radiations into latent, sensible and ground heat fluxes (energy cycle). It is therefore essential to correctly represent this amount of water contained in the soil in hydrological models.

Ground measurements of soil moisture are broadly used to monitor the hydrological cycle of a specific region. Like all in situ stations, the soil moisture probes need to be maintained and are most of the time installed for a limited amount of time. Moreover, the number of in situ measurements stays scarce, especially in tropical regions where the maintenance is even more complicated. Soil moisture monitoring from space has thus been developed for a larger/wider spatial coverage and assures continuity in time as long as the space mission is still operating. These two types are very complemen- 
tary with in situ stations being able to directly measure soil moisture profiles at different depths and also used for satellite soil moisture validation.

In order to take advantage of these dedicated space missions, the hydrological model simulations can be merged with available observations through data assimilation. This technique has already been widely used by weather forecast models at regional and global scales, using remote sensing observations and ground measurements to improve weather forecasting.

Numerous studies have been devoted to use soil moisture assimilation into hydrological and land surface models for various applications. With the availability of more than 35 years of soil moisture at the global scale derived from a series of satellites (SMMR, SSM/I, TRMM-TMI, AMSRE, ASCAT, Windsat; Liu et al., 2011, 2012; Wagner et al., 2012), the soil moisture CCI (Climate Change Initiative by ESA; Hollmann et al., 2013) has been assimilated in many models for hydrological purposes such as streamflow simulation (Pauwels et al., 2001, 2002), flood events prediction via runoff simulation (Brocca et al., 2010, 2012), drought prediction (Kumar et al., 2014) and root zone soil moisture simulations (Draper et al., 2012; Renzullo et al., 2014; Parrens et al., 2014) for a better prediction of agricultural yields (Chakrabarti et al., 2014). Han et al. (2012) voluntarily degraded the precipitation input and showed that soil moisture, water table depth (WTD) and evapotranspiration simulations could be improved by assimilating surface soil moisture. As in most of the soil moisture assimilation studies, Ridler et al. (2014) have also found that it improves the distribution of the soil moisture simulations.

More recently, Wanders et al. (2014) and Lievens et al. (2015) assimilated the Soil Moisture Ocean Salinity (SMOS) soil moisture product into hydrological models. The first study assessed the impact of the joint assimilation of remotely sensed soil moisture (ASCAT (Advanced SCATterometer), AMSR-E (Advanced Microwave Scanning Radiometer - Earth observing system) and SMOS (Soil Moisture and Ocean Salinity)) on the flood predictions over the upper Danube basin using the distributed hydrological LISFLOOD model for operational services. They showed that soil moisture observations improved the quality of flood alerts, both in terms of timing and of peak heights. They also reduced the number of false flood alarms. Lievens et al. (2015) assimilated the SMOS soil moisture product into the VIC (Variable Infiltration Capacity) model over the MurrayDarling basin, Australia, which is around 1 million $\mathrm{km}^{2}$. While the model was calibrated using 169 discharge stations, the streamflow simulations were good at the monthly scale but poor on a daily basis. Assimilation of soil moisture improved the soil moisture simulations, and hence the runoff generation, which finally had a positive impact on the streamflow simulations, especially during the runoff peak time periods.
Assimilation is of particular interest for regions where water management is vital, whereas in situ hydrological data are scarce. This is the case in the West African region, which faces major water-related risks (drought, floods, famine, diseases) threatening the population safety and slowing down the economical development. At the same time, the region is notoriously known to be lacking in in situ hydrological data, which limits the possibility to properly address the water management issues.

For operational applications, real-time hydrological modeling is needed and this requires one to have real-time observations and information. Various real-time observations exist but may lack accuracy with biases that will impact all the hydrologic variables, and reanalyzed versions are made available several weeks to months after the actual observations. Precipitation forcing is the main source of uncertainty in hydrological modeling.

We propose a methodology to correct for the inaccurate amount of water brought by the real-time precipitation forcing by assimilating the SMOS soil moisture products. They are available within 10 days after the observations, and could be used for hydrological applications until the reanalyzed precipitation are released. This work will focus on the Ouémé catchment located in Benin, West Africa, which is presented in the first part along with the rainfall and soil moisture satellite products. The second part describes the hydrological model and the data assimilation method. Then the impact on the simulations of the soil moisture, the water table depth and the streamflow is discussed.

\section{Study area and satellite data}

\subsection{The Ouémé catchment and the in situ measurements}

The Ouémé catchment is located in Benin, West Africa, and is part of the AMMA-CATCH observatory (African Monsoon Multidisciplinary Analysis - Coupling the Tropical Atmosphere and the Hydrological Cycle; Lebel et al. (2009); http://www.amma-catch.org), whose objective is to study the hydrological impact of climate and anthropogenic changes. With a size of $12000 \mathrm{~km}^{2}$, the Ouémé catchment is mainly covered by savanna, forests and cultures. The rainy season spreads from April to October for an annual amount of around $1250 \mathrm{~mm}$. Streamflow is permanent from July to November. The basin is on basement. The hard-rock aquifer is unconfined and its recharge is annual. This basin is highly instrumented in order to monitor the water cycle and the vegetation dynamic in this sub-humid region.

Soil moisture is measured at three locations indicated by red crosses in Fig. 1: Nalohou, Belefoungou and Bira. Every hour, time-domain reflectometry sensors measure the soil response to an electric pulse at various depths (from $5 \mathrm{~cm}$ to $1.2 \mathrm{~m}$ ). Soil moisture values can be retrieved after correc- 

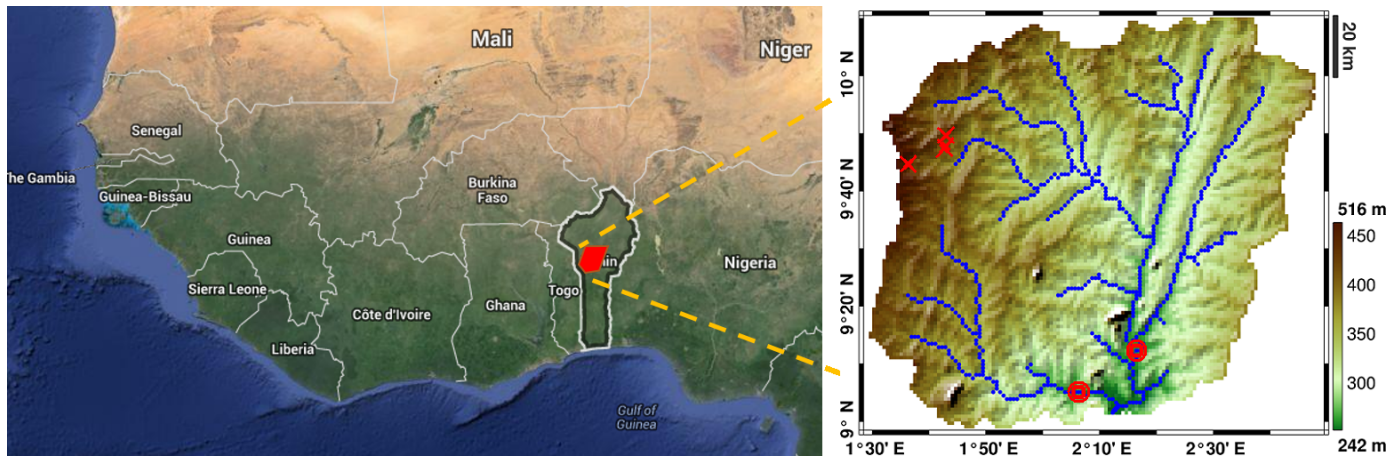

Figure 1. The Ouémé catchment is located in Benin, West Africa. Indicated on the right panel is the location of three soil moisture stations in the northwestern part (red crosses) where water table depth is also measured, and two streamflow sensors installed in the southern part (red circles, the outlet total streamflow being the sum of the two stations measurements).

tion for the soil temperature impact and by using wet and dry samples from the different ground sites. For two of these sites, flux stations are also installed measuring the evapotranspiration every $30 \mathrm{~min}$ using eddy correlation sensors.

The water table, which is defined as the interface between unsaturated and saturated soil, is measured manually every 2 days on a network of observation wells close to the soil moisture sites (Seguis et al., 2011).

Water levels from the rivers are measured every hour at two locations (indicated by the two red circles in Fig. 1) representing the outlets of the two sub-basins of the Ouémé catchment: Cote 238 and Beterou. For each site, a calibration has been realized to convert the water level into a streamflow value using an acoustics Doppler current profiler. The total streamflow is supposed to be the sum of the measurements at these two points as the contribution between the real outlet of the whole basin and the points of measurement is negligible.

The rainfall monitoring is ensured by a dense network of rain gauges (tipping bucket). For the study of years 2010 2012,33 evenly distributed rain gauges were operating. Their measurements have been treated in order to produce $1 \mathrm{~h}$ rainfall series that have then been spatially interpolated over a regular $0.05^{\circ}$ resolution grid based on Lagrangian kriging (Vischel et al., 2011). Since the rain gauge network is dense enough, the use of interpolated rain fields to force hydrological models is relevant and can help to produce simulations of reference (Vischel and Lebel, 2007; Gascon et al., 2015).

\subsection{Satellite rainfall products}

In most cases and more particularly for tropical and semiarid regions, there are not enough rain gauges to cover the entire basin and precipitation observed by satellite can be used. Many satellite products are available and three have been used in this study.

The PERSIANN (Precipitation Estimation from Remotely Sensed Information using Artificial Neural Networks, v. 300 and 301; Hsu et al., 1997; Sorooshian et al., 2000) product is an estimation of the rainfall rate, used here at a $0.25^{\circ}$ resolution every $3 \mathrm{~h}$, based on infrared satellite observations coupled to ground observations from gauges and radars operating at various frequencies. Some studies have already shown that this rainfall product does not perform well everywhere (Ward et al., 2011; Thiemig et al., 2012).

A second satellite product has been used for precipitation forcing data: the TRMM (Tropical Rainfall Measuring Mission) Near-Real-Time 3B42RT (v7; Huffman et al., 2007), which combines microwave and infrared satellite observations and is available at a $0.25^{\circ}$ resolution and a $3 \mathrm{~h}$ time step. This product has been widely used in various hydrological studies (Khan et al., 2011; Li et al., 2012) and has the advantage to combine two sources of data compared to the PERSIANN product. For the sake of simplicity, the TRMM Near-Real-Time 3B42RT product is referred as the TRMM product in the following.

CMORPH (CPC MORPHing from NOAA; Joyce et al., $2004)$ is the third precipitation product used here. This method uses rainfall estimates that have been derived from low-orbit satellite microwave observations, and infrared observations from geostationary satellites in order to produce a merged and unique rainfall data set. The CMORPH product that has been selected is available at a $0.25^{\circ}$ resolution and a $3 \mathrm{~h}$ time step.

PERSIANN, TRMM and CMORPH are the quasi-realtime precipitation forcing products used in this study (referenced as RT). They usually are available within a few hours after the actual observations. Their post-adjusted or reanalyzed versions (PERSIANN-CDR, TRMM-v7 and CMORPH-v1) are generated by adding external information like in situ rain gauge measurements or soil radar observations (referenced as RE). They are generally more accurate but are only available 2 to 3 months after the actual observations, which is not compatible with real-time applications most of the time. Figure 2 shows the cumulative amounts of water brought by the different satellite products compared to the in situ measurements in average over the whole basin. 

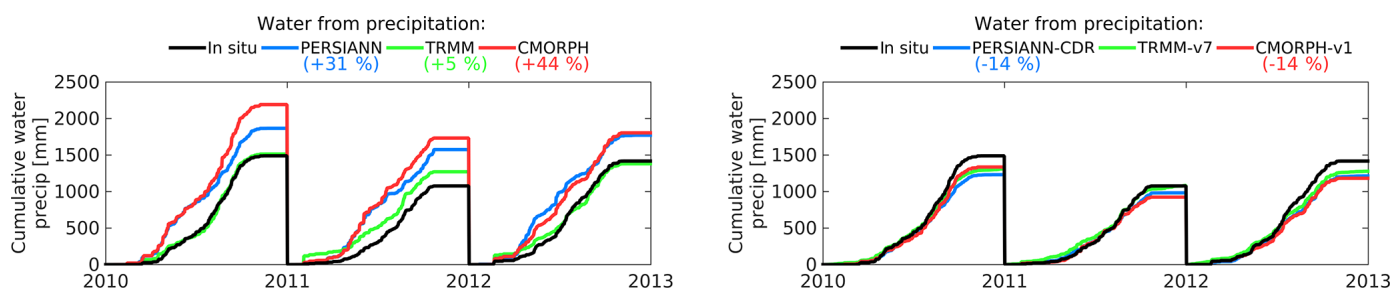

Figure 2. Cumulative average precipitation amount over the whole basin from the in situ network (black) and the three satellite product from quasi-real-time versions (left panel) and their reanalyzed versions (right panel): PERSIANN (blue), TRMM (green) and CMORPH (red).

While the RT products (left panel) overestimate the precipitation amount, the reanalyzed products slightly underestimate (right panel). The largest difference between in situ and satellite rainfall occurs in the second quarter of the year for the PERSIANN and CMORPH products, which is just before the monsoon period and might saturate the soil earlier than it should, leading to high values of runoff and discharge. For all the RT products, the dry season is not well represented even if the rainfall amount is much lower than during the rainy season. These positive biases were already identified in Gosset et al. (2013) and Casse et al. (2015). The distribution of the precipitation of the reanalyzed products is, however, much improved in the reanalyzed products (not shown here).

\subsection{SMOS soil moisture product}

The SMOS mission has been producing soil moisture products for more than 5 years, observing the entire globe every 3 days at a resolution of around $40 \mathrm{~km}$. Thanks to the multi-angular observations and the sensitivity of the L-band frequency to the soil water content, the soil moisture is retrieved with a target accuracy of $0.04 \mathrm{~m}^{3} \mathrm{~m}^{-3}$. More details can be found about the soil moisture retrieval algorithm in Kerr et al. (2012).

The SMOS level 3 soil moisture product (second reprocessing, v. 2.7, 1-day product; Jacquette et al., 2010) used in this study is provided by CNES-CATDS (Centre Aval de Traitement des Données SMOS) on the EASE-Grid 2.0 (Equal-Area Scalable Earth) at $25 \mathrm{~km}$ resolution. This product is usually available within 10 days. In Louvet et al. (2015), it was found that the SMOS L3 product is the most suitable and available satellite soil moisture product compared to in situ measurements collected in West Africa from 2010 to 2012 .

\section{Model and data assimilation}

\subsection{DHSVM model}

For the Ouémé catchment, Seguis et al. (2011) shows a major contribution of lateral water flows in the hydrological processes, especially during the spring season. The Distributed Hydrology Soil Vegetation Model (DHSVM, developed at the University of Washington; Wigmosta et al., 1994) has been selected for its capability of water lateral redistribution from and to the neighboring pixels.

DHSVM solves the energy and water balances at each grid cell and time step with a physically based model representing the effect of topography, soil and vegetation. The outputs are the soil moisture, the snow quantity (not used nor showed here), the streamflow, the evapotranspiration and the runoff. This model has already been used in many previous studies (Whitaker et al., 2003; Cuo et al., 2006; Cuartas et al., 2012; Du et al., 2014; Gascon et al., 2015) showing its capability to simulate various hydrological components such as the snowpack, the streamflow, the water table depths or the soil moisture. All these studies also emphasized the importance of the model parameter calibration step and the accuracy of the meteorological input data.

DHSVM has been used in this study at a resolution of $1 \mathrm{~km}$ with an hourly time step and four soil layers at the following depths: 1, 5, 40 and $80 \mathrm{~cm}$. The first layer has been set for numerical reasons, the second is used for the assimilation, and the two deeper layers are used for validation with in situ measurements. It also needs meteorological inputs for the following variables: relative humidity, air temperature, wind speed, pressure, shortwave and longwave radiation. The reanalysis MERRA (Modern-Era Retrospective analysis for Research and Applications) products from NASA have been used in this study (Rienecker et al., 2011). These products are available hourly at a $1 / 2$ and $2 / 3^{\circ}$ resolution in latitude and longitude, and have been produced using the Goddard Earth Observing System Model (GEOS-5, version 5) and the Atmospheric Data Assimilation System (ADAS, version 5.2.0).

The DHSVM model has many parameters, which could be measured in situ or, if no measurement is available, can be estimated based on soil characteristics and vegetation covers. Previous studies (Whitaker et al., 2003; Cuo et al., 2006; Cuartas et al., 2012; Du et al., 2014) described precisely their DHSVM model parameter values using in situ radiation, soil moisture and streamflow measurements for calibration. It was often noticed that it was difficult to obtain good soil moisture and streamflow simulations simultaneously, and that streamflow simulations could be improved at the expense of the soil moisture simulations (Cuo et al., 2006). 
Table 1. DHSVM soil and vegetation parameter values (understory and overstory) after calibration. The marker * indicates the parameters that have been re-estimated for the whole basin compared to Gascon et al. (2015).

\begin{tabular}{|c|c|c|c|c|}
\hline \multicolumn{2}{|c|}{ Soil parameters } & \multicolumn{3}{|c|}{ Vegetation parameters } \\
\hline & & & Under. & Over. \\
\hline $\begin{array}{l}\text { Lateral saturated hydraulic } \\
\text { conductivity* }\left[\mathrm{m} \mathrm{s}^{-1}\right]\end{array}$ & $5 \times 10^{-2}$ & $\begin{array}{l}\text { Canopy coverage [fraction] } \\
\text { trunk space [fraction] }\end{array}$ & & $\begin{array}{l}0.9 \\
0.4\end{array}$ \\
\hline $\begin{array}{l}\text { Exponential decrease rate } \\
\text { of lateral saturated } \\
\text { hydraulic conductivity* }[-]\end{array}$ & 2 & $\begin{array}{l}\text { Aerodynamic extinction } \\
\text { factor for wind through } \\
\text { overstory [fraction] }\end{array}$ & & 3.5 \\
\hline Max. infiltration rate $\left[\mathrm{m} \mathrm{s}^{-1}\right]$ & $2 \times 10^{-4}$ & Radiation attenuation by & & 0.5 \\
\hline Soil surface albedo $[-]$ & 0.1 & Vegetation [fraction] & & \\
\hline Porosity* [fraction, 4 layers] & $0.5,0.5,0.5,0.5$ & Vegetation height $[\mathrm{m}]$ & 0.5 & 6 \\
\hline $\begin{array}{l}\text { Bulk density } \\
{\left[\mathrm{kg} \mathrm{m}^{-3}, 4 \text { layers }\right]} \\
\text { Field capacity* } \\
{\left[\mathrm{m}^{3} \mathrm{~m}^{-3}, 4 \text { layers }\right]}\end{array}$ & $\begin{array}{l}1485,1485 \\
1485,1485 \\
0.15,0.20 \\
0.25,0.35\end{array}$ & $\begin{array}{l}\text { Fraction of shortwave } \\
\text { radiation photosynthetically } \\
\text { active }\left(R_{\mathrm{pc}}\right) \\
\text { Root zone depths }[\mathrm{m}]\end{array}$ & $0.01,0.0$ & $5,0.40,1.0$ \\
\hline $\begin{array}{l}\text { Wilting point* } \\
{\left[\mathrm{m}^{3} \mathrm{~m}^{-3}, 4 \text { layers }\right]}\end{array}$ & $\begin{array}{l}0.02,0.04 \\
0.08,0.12\end{array}$ & $\begin{array}{l}\text { SM threshold above which } \\
\text { transpiration is not }\end{array}$ & 0.10 & 0.30 \\
\hline $\begin{array}{l}\text { Vertical saturated hydraulic } \\
\text { conductivity* }\left[\mathrm{m} \mathrm{s}^{-1}, 4 \text { layers }\right]\end{array}$ & $\begin{array}{l}10^{-7}, 10^{-6} \\
10^{-6}, 10^{-6}\end{array}$ & $\begin{array}{l}\text { Restricted }\left[\mathrm{m}^{3} \mathrm{~m}^{-3}\right] \\
\text { vapor pressure deficit }\end{array}$ & 3000 & 2500 \\
\hline $\begin{array}{l}\text { Thermal conductivity } \\
\text { [W m }{ }^{-1} \mathrm{~K}^{-1}, 4 \text { layers] }\end{array}$ & $\begin{array}{l}7.114,7.114 \\
7.114,7.114\end{array}$ & $\begin{array}{l}\text { Threshold above which } \\
\text { stomatal closure occurs [Pa] }\end{array}$ & & \\
\hline $\begin{array}{l}\text { Thermal capacity } \\
{\left[\mathrm{J} \mathrm{m}^{-3} \mathrm{~K}^{-1}, 4 \text { layers }\right]}\end{array}$ & $\begin{array}{l}1.4 \times 10^{6}, 1.4 \times 10^{6} \\
1.4 \times 10^{6}, 1.4 \times 10^{6}\end{array}$ & & & \\
\hline
\end{tabular}

In Gascon et al. (2015), DHSVM parameterization was realized using in situ streamflow measurements at the Cote 238 station for 2005 , which represents $25 \%$ of the whole basin (Beterou station being on the main course of the Ouémé river). This parameterization has been used as a starting point for this study. Here, the model has different soil layers and has been calibrated using in situ measurements from 2010 (soil moisture from the three stations, streamflow at the outlet, and evapotranspiration from one station). In order to ingest the correct amount of water for the calibration process, the interpolated in situ rainfall data have been used. Table 1 represents the main soil and vegetation characteristics used in this study for the DHSVM model after calibration for the whole basin. These parameter values have been optimized using a semi-automatic protocol; i.e., multiple sets of values have been tested and the one giving the best performance has been chosen. Model outputs have been evaluated at different locations in the basin (from various stations) using soil moisture $\left(R=0.81\right.$, RMSE $\left.=0.084 \mathrm{~m}^{3} \mathrm{~m}^{-3}\right)$, streamflow $(R=0.94$, RMSE $\left.=81.7 \mathrm{~m}^{3} \mathrm{~s}^{-1}, \mathrm{Nash}=0.87\right)$ and evapotranspiration $\left(R=0.81, \mathrm{RMSE}=166.7 \mathrm{~W} \mathrm{~m}^{2}\right)$ in situ measurements.
As mentioned in Bitew and Gebremichael (2011), calibrating a model using biased satellite precipitation will lead to a set of parameters that will compensate for the modified runoff generated by the under or overestimated volume of water brought by the satellite product compared to the in situ measurements. Adjusting the model parameters can compensate for the rainfall errors but the global water budget will be deteriorated and the other hydrological processes will be disturbed. For this reason, the model calibration has only been performed with the in situ precipitation, which leads to a correct partitioning of the precipitation between infiltration and runoff. Similar results were found when adjusted satellite products were used and close statistic scores were obtained (see Fig. 3 for water table depth and Fig. 4 for streamflow simulations). The term open-loop refers to simulations with no assimilation.

One of the five outputs of DHSVM is the water table depth. Groundwater is an important resource, especially in West Africa where most of the drinking water comes from the ground. Moreover, the precipitation interannual variability can be important $(1560 \mathrm{~mm}$ in 2010 followed by only $1100 \mathrm{~mm}$ in 2011 and $1450 \mathrm{~mm}$ in 2012 from the in situ rain gauge measurements), which has a strong impact on ground- 


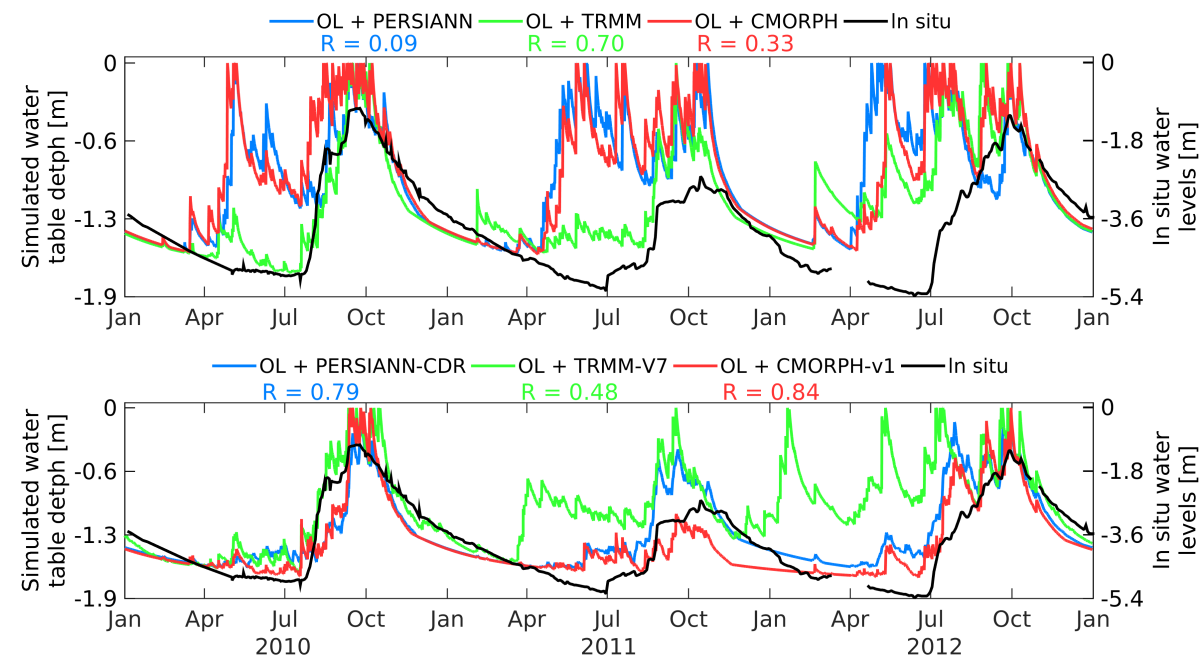

Figure 3. Open-loop (OL) water table depth simulations using the RT (top panel) and reanalyzed (bottom panel) satellite precipitation products as forcing compared to in situ measurements at Nalohou. For comparison, the water table depth simulations using in situ precipitation as forcing (not shown here) lead to a correlation of 0.76 .
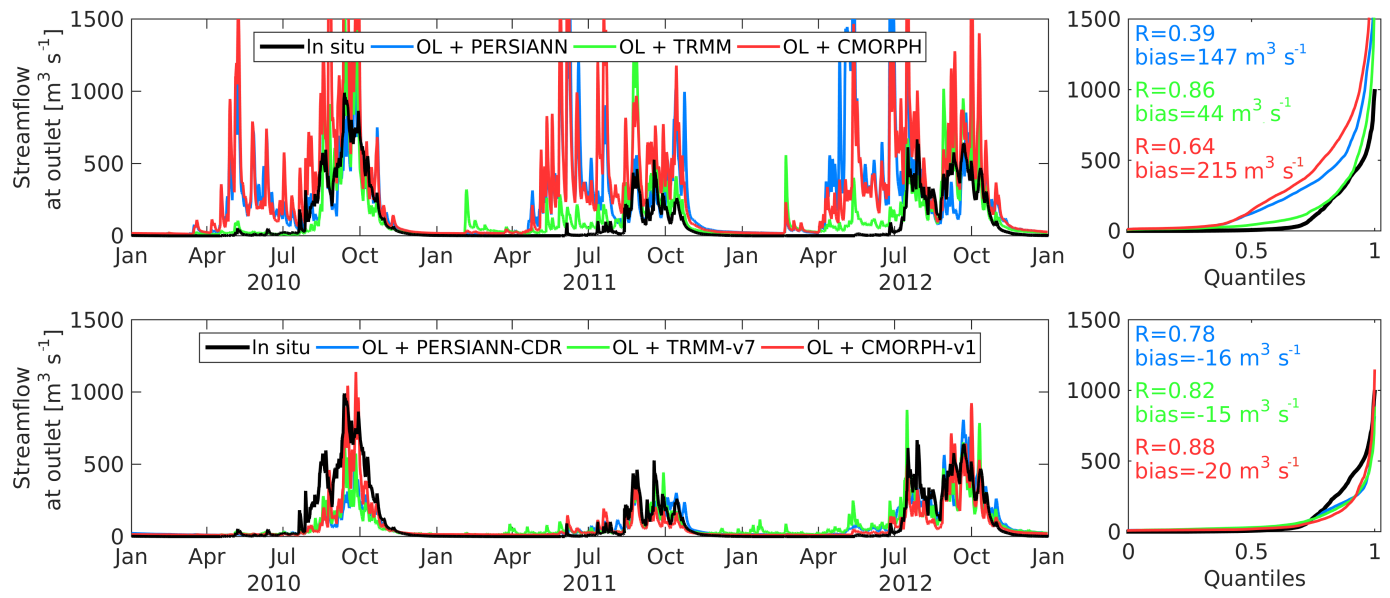

Figure 4. Open-loop (OL) streamflow simulations using the RT and reanalyzed satellite precipitation products as forcing. Statistics are given on the right panel. For comparison, the streamflow simulations using in situ precipitation as forcing (not shown here) lead to a correlation of 0.92 for a bias of $32 \mathrm{~m}^{3} \mathrm{~s}^{-1}$.

water recharge. The water table depth can vary between the soil depth and the ground surface (in the latest case, an exfiltration or a flooding can happen). Sensitivity tests have been realized for the Ouémé catchment with many years of spinup for various soil depth values and the maximum water table depth was always found around $1.90 \mathrm{~m}$. After these yearly spin-ups, water was filling the soil until its natural equilibrium. The water table depth does not depend on the soil depth but on the ability of the model to evacuate this saturated water through the defined hydrological network, the root density and the topography (physical processes are explained in Seguis et al., 2011).

Figure 3 shows the simulations of the water table depth using the different precipitation products at Nalohou (sta- tion selected for the availability of its measurements along the three years of study, and can be compared to simulations from the closest model $1 \mathrm{~km}^{2}$ pixel). Simulated water table depths and water levels from wells are not quite comparable but they should follow the same time evolution (certainly because of the difference in porosity values set in the model and what is observed in reality). In order to compare both quantities, they are represented on the same graph but not at the same scale. The left $y$ axis represents the depth of the water as simulated by the model, whereas the right $y$ axis represents the in situ water level as measured in the observation well with a maximum of $5.40 \mathrm{~m}$. Correlation scores are not impacted by scaling and they are indicated directly on the figure. 
Using the RT precipitation (top panel), the water table depth is correctly simulated until the first rainfalls when the soil is quickly saturated due to the inaccurately high amount of water brought by the RT products, which then percolates to the deep soil layers. The soil is completely saturated in early May with a simulated water table reaching the surface. The correlation scores are very low for PERSIANN and CMORPH (0.09 and 0.33), whereas the TRMM product gives fair simulations with a correlation of 0.70 . Using the reanalyzed precipitation (bottom panel), the time evolution is improved and most of the early peaks are smoothed. The correlations are higher for PERSIANN (0.79) and CMORPH (0.84), whereas it is lower for TRMM (0.48) due to inaccurate precipitation event in spring 2011 and in winter-spring 2012.

Figure 4 shows the simulations of the streamflow at the outlet of the basin compared to the in situ measurements. Using the RT precipitation (top panel), the streamflow is highly impacted by the runoff caused by the saturated soil from the inaccurate rainfall events, and it becomes very sensitive to any additional amount of water. This is the reason for these high and quick changes in the streamflow time series. When the reanalyzed precipitation is used (bottom panel), the time evolution is much closer to the in situ measurements. The simulations are a bit underestimated in 2010, but then correct for 2011 and 2012. PERSIANN and CMORPH simulations are improved by the reanalysis with a correlation from 0.39 and 0.64 to 0.78 and 0.88 , respectively, with a bias divided by 10. Correlation using TRMM is a bit lower using the reanalyzed product (from 0.86 to 0.82 ) but the bias is still divided by 3 . The simulations using the in situ precipitation (not shown here) give a correlation of 0.92 for a bias of $32 \mathrm{~m}^{3} \mathrm{~s}^{-1}$, which is a bit higher than the reanalyzed precipitation products for the correlation but a bit lower for the bias. The statistics' performances from the reanalyzed products and from the in situ precipitation are about the same, showing that the parameterization of the model is adequate for both forcing.

It is not expected from the RT precipitation products to generate simulations as good as the reanalyzed precipitation, but Figs. 3 and 4 show the room for improvement that can be realized between the two versions of the satellite precipitation products by the assimilation.

\subsection{Assimilation method: the optimal interpolation}

SMOS soil moisture is assimilated into the DHSVM model using an optimal interpolation method (simplification of the Kalman filter where the errors are assumed to be known). In this study, the "3D-Cm" method proposed in De Lannoy et al. (2010) and successfully used in Sahoo et al. (2013), is applied here. The "3D-Cm" scheme consists in assimilating multiple coarse-scale observations $(25 \mathrm{~km})$, which implies an aggregation of the model from the fine scale $(1 \mathrm{~km})$ to the SMOS scale but avoids artificial transitions at the pixel boundaries by using multiple coarse-scale observations to update the finer-scale simulations. Some of the key equations of the assimilation method are detailed in this article but more information can be found in De Lannoy et al. (2010) or in Sahoo et al. (2013).

Based on the difference between the simulations and the observations, the model background predictions are updated depending on their respective error covariances. Ensemble methods can estimate these error covariances from a Monte Carlo ensemble generation but in this study, a simpler method has been applied and fixed values of the error covariances are used.

Before being assimilated and for an optimal analysis (Yilmaz and Crow, 2013), the SMOS soil moisture product has been rescaled to remove any systematic bias using the openloop model simulations. In this study, a CDF (cumulative density function) matching at SMOS scale has been applied for each pixel independently for each year according to the open-loop variability. Also, the ascending (06:00 LST - local solar time) and the descending (18:00 LST) observations have been treated separately.

At each time step $i$ a SMOS observation is available, the forecast state vector $\hat{\boldsymbol{x}}_{i}^{-}$including the soil moisture at the four model soil depths $(1,5,40$ and $80 \mathrm{~cm})$ is mapped from the fine model scale $(1 \mathrm{~km})$ to the coarse SMOS scale $(25 \mathrm{~km})$ to calculate the prediction at the observation scale $H \hat{\boldsymbol{x}}_{i}^{-}$, where $H$ is called the observation operator. As in De Lannoy et al. (2010) or Sahoo et al. (2013), a simple spatial mean is applied here. The difference between the observation and the prediction at the coarse scale, called the innovation $\left(y_{i}-H \hat{\boldsymbol{x}}_{i}^{-}\right)$, is used to update the finer model pixels $\hat{x}_{i}^{+}$ called the analysis using a gain matrix $\mathbf{K}$. The update equation at time step $i$ for a given fine-scale pixel $k$ is as follows:

$\hat{x}_{i}^{k+}=\hat{x}_{i}^{k-}+K_{i}^{k}\left[y_{i}-H \hat{\boldsymbol{x}}_{i}^{-}\right]$,

where the gain matrix $\mathbf{K}$ depends on the model error covariance $B$ and the observation error covariance after rescaling $R$ :

$\mathbf{K}=\frac{B H^{T}}{H B H^{T}+R}$.

The model error covariance matrix $\mathbf{B}$ is calculated separately for each pixel of the model grid based on the DHSVM open-loop simulations $\left(B_{i j}=\operatorname{Cov}\left(\mathrm{SM}_{i}, \mathrm{SM}_{j}\right)\right)$. The average B matrix is as follows:

$\mathbf{B}=\left[\begin{array}{llll}0.022 & 0.015 & 0.010 & 0.003 \\ 0.015 & 0.019 & 0.011 & 0.003 \\ 0.010 & 0.011 & 0.012 & 0.005 \\ 0.003 & 0.003 & 0.005 & 0.006\end{array}\right]\left(\mathrm{m}^{3} \mathrm{~m}^{3}\right)^{2}$

The SMOS observation error covariance matrix $\mathbf{R}$ is evaluated for each node of the SMOS grid using all the available SMOS observations. $\mathbf{R}$ is supposed to be diagonal and represents the variance of the observations. The average variance of the SMOS observations is $0.017\left(\mathrm{~m}^{3} \mathrm{~m}^{-3}\right)^{2}$. 
Finally, the observation matrix $\mathbf{H}$ consists of four columns (for the four soil layers) times the number of available observations for the number of lines. Since the assimilation is performed on the second soil layer, the second column $\mathbf{H}$ should be filled with the same equal value if all SMOS observations had the same influence on the model grid point of interest (sum of these values equal to 1). For this reason, a weighing function is used depending on the distance between the SMOS observation and the concerned model point such as shown in Fig. 5.

Here, $y_{i}$ contains as many SMOS observations as are within a given radius $(60 \mathrm{~km})$ and those observations have a larger impact if they are closer to the considered model pixel to update. As in Reichle and Koster (2003) and De Lannoy et al. (2010), a fifth-order polynomial function (Eq. (4.10) of Gaspari and Cohn, 1999) based on the distance between two points and on a compact support radius is applied to weigh the influence of SMOS observations in $H$ (Gaspari function, red line in Fig. 5). This equation is really close to the SMOS mean weighting function used to model the antenna pattern in the SMOS retrieval algorithm (Kerr et al. (2015), blue line in Fig. 5).

The SMOS observations are assimilated in the second soil layer of the model $(1-5 \mathrm{~cm})$ since it is more representative of what is observed by the SMOS instrument (Kerr et al., 2012). The correlations between the different soil layers being contained in $K$, the other soil layers $(1,40$ and $80 \mathrm{~cm})$ are also updated during the same time step but with a lower influence from the SMOS observations. The other model variables such as the evapotranspiration and the streamflow are not updated through the assimilation step but are updated with the propagation of these modifications in the model, i.e., if water is removed from the ground, the lateral subsurface flow and the streamflow should decrease too.

\subsection{Statistics metrics}

In order to quantify the performances of the model simulations and the impact of the SMOS soil moisture assimilation, five statistics metrics have been chosen in this study: the temporal correlation $R$, the bias, the standard deviation of the difference between the simulations and the in situ measurements (sdd), the root mean square errors $\left(\mathrm{RMSE}=\sqrt{\mathrm{bias}^{2}+\mathrm{sdd}^{2}}\right)$ and the Nash model efficiency coefficient as defined in Nash and Sutcliffe (1970) for streamflow simulation skill. These statistics have been computed using all common dates available.

\section{Results and discussion}

This section presents the impact of the SMOS soil moisture assimilation on different variables: soil moisture at multiple depths (control variables) at the Bira station, water table depth at the Nalohou station, and streamflow at the out-

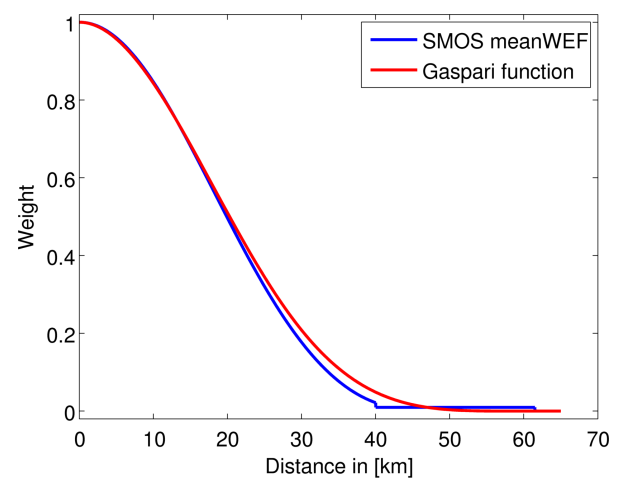

Figure 5. Weighing functions for the observation matrix $\mathbf{H}$ comparing the function used for the SMOS antenna pattern and the Gaspari function used in this study.

let. The simulations and performances after assimilation are compared to the open-loop simulations in the objective to reach those from the reanalyzed precipitation products.

\subsection{Correction of the control variable: the soil moisture}

The first variables to be impacted by the assimilation of SMOS products are the ones directly contained in the state vector of the assimilation scheme; i.e., the soil moisture of the four defined soil layers at $1,5,40$ and $80 \mathrm{~cm}$. Soil moisture simulations are shown in Fig. 6 at $5 \mathrm{~cm}$ depth for two time periods: the upper panel represents the time series of March-April 2011 (beginning of the rain season), and the lower panel May-June 2012 (wet season). The left side shows the open-loop simulations, whereas the afterassimilation results are on the right side. For visual clarity, the 3 years of simulations are not shown here but these two time periods are representative of the effect of the assimilation on the soil moisture variable.

As mentioned before, the RT satellite rainfall products bring too much water during the winter and spring seasons. The first time period (top panel of Fig. 6) is a good example of a soil moisture increase after a rainfall detected by the satellite product (at the beginning of March for example), which has not happened in reality. The simulated soil moisture is thus impacted by this fake rain event with an increase. By assimilating SMOS soil moisture product at the surface, the impact of this wrong rainfall event is smoothed but has not completely disappeared. The wet season example also shows the same process. These wrong increases cannot be corrected by the assimilation but the drying phases can be fastened as post-event corrections.

Table 2 gathers the statistic scores of all the precipitation cases (RT, RT after assimilation, and RE) for the 3 years and the three layers at the Bira station. As it can be seen in Fig. 6, the continuity in the soil moisture time series cannot always be preserved by the assimilation method applied here, which results in abrupt changes before and after the time step when 
Table 2. Statistics of the simulated soil moisture at 3 depths $(5,40$ and $80 \mathrm{~cm})$ compared to the in situ measurements at the Bira station for 2010-2012. Three cases are considered: open-loop simulations using real-time satellite precipitation (RT), assimilation of SMOS soil moisture with real-time precipitation (RT + SMOS) and open-loop simulation using reanalyzed precipitation (RE). Bias, standard deviation of the difference (sdd) and root mean square error (RMSE) are in $\mathrm{m}^{3} \mathrm{~m}^{-3}$, the correlation $(R)$ is dimensionless. Bold font is used when the bias is improved by the assimilation.

\begin{tabular}{|c|c|c|c|c|c|c|c|c|c|}
\hline \multirow[t]{2}{*}{ SM } & \multicolumn{3}{|c|}{ PERSIANN } & \multicolumn{3}{|c|}{ TRMM } & \multicolumn{3}{|c|}{ CMORPH } \\
\hline & RT & $\mathrm{RT}+\mathrm{SMOS}$ & $\mathrm{RE}$ & RT & $\mathrm{RT}+\mathrm{SMOS}$ & $\mathrm{RE}$ & RT & $\mathrm{RT}+\mathrm{SMOS}$ & $\mathrm{RE}$ \\
\hline \multicolumn{10}{|c|}{$(5 \mathrm{~cm})$} \\
\hline$R$ & 0.60 & 0.73 & 0.81 & 0.72 & 0.81 & 0.54 & 0.76 & 0.78 & 0.76 \\
\hline bias & 0.091 & 0.062 & 0.073 & 0.051 & 0.051 & 0.123 & 0.089 & 0.056 & 0.041 \\
\hline sdd & 0.119 & 0.091 & 0.091 & 0.098 & 0.082 & 0.102 & 0.102 & 0.086 & 0.088 \\
\hline RMSE & 0.150 & 0.110 & 0.117 & 0.110 & 0.096 & 0.160 & 0.136 & 0.103 & 0.097 \\
\hline \multicolumn{10}{|c|}{$(40 \mathrm{~cm})$} \\
\hline$R$ & 0.62 & 0.65 & 0.89 & 0.75 & 0.72 & 0.65 & 0.76 & 0.67 & 0.87 \\
\hline bias & 0.119 & 0.052 & 0.056 & 0.086 & 0.071 & 0.129 & 0.128 & 0.064 & 0.033 \\
\hline sdd & 0.085 & 0.099 & 0.058 & 0.068 & 0.094 & 0.064 & 0.072 & 0.101 & 0.058 \\
\hline RMSE & 0.146 & 0.112 & 0.081 & 0.110 & 0.117 & 0.144 & 0.147 & 0.120 & 0.067 \\
\hline \multicolumn{10}{|c|}{$(80 \mathrm{~cm})$} \\
\hline$R$ & 0.64 & 0.49 & 0.63 & 0.52 & 0.42 & 0.36 & 0.69 & 0.50 & 0.57 \\
\hline bias & 0.194 & 0.102 & 0.114 & 0.154 & 0.136 & 0.192 & 0.200 & 0.131 & 0.068 \\
\hline sdd & 0.064 & 0.126 & 0.084 & 0.083 & 0.115 & 0.088 & 0.056 & 0.119 & 0.097 \\
\hline RMSE & 0.204 & 0.162 & 0.142 & 0.175 & 0.178 & 0.211 & 0.208 & 0.177 & 0.119 \\
\hline
\end{tabular}
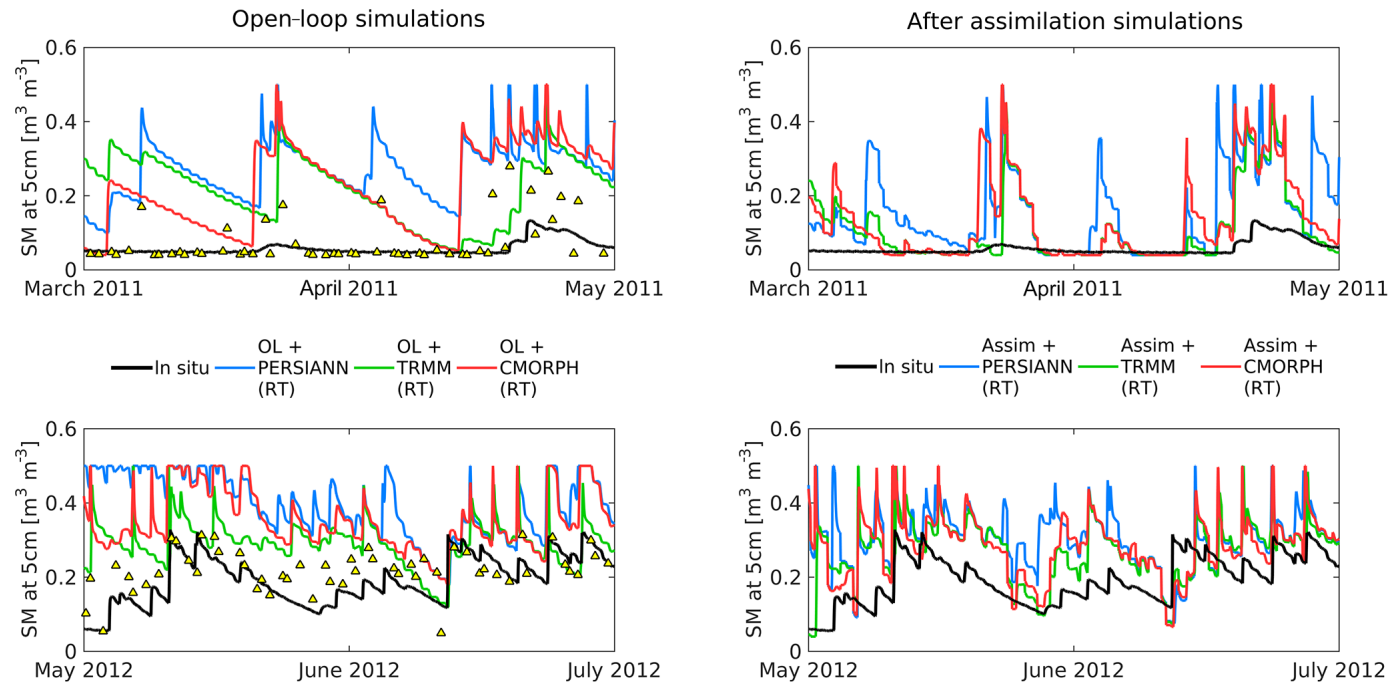

Figure 6. Comparison between the simulations of soil moisture at $5 \mathrm{~cm}$ depth at the Bira station at two different time periods: dry season in 2011 (upper panel), and the beginning of the raining season in 2012 (lower panel). The open-loop simulations are represented on the left whereas the simulated soil moisture after assimilation are on the right. The different rainfall products are indicated with various colors. Assimilated SMOS observations are indicated by yellow triangles on the left panel.

the assimilation is performed. This discontinuity has a negative artificial impact on the correlation, the standard deviation and the root mean square error. The bias is the only statistical metric that can be used to truly assess the impact of the as- similation on the soil moisture variable. The other statistics are shown for indication in Table 2.

Using the RT satellite precipitation products, the bias is always reduced after the assimilation. At $5 \mathrm{~cm}$ depth, it is improved by $0 \%$ (TRMM) to $37 \%(\mathrm{CMORPH})$, at $40 \mathrm{~cm}$ 
Table 3. Statistics of the simulated water table depth (WTD) compared to the in situ measurements at the Nalohou station for 2010-2012. Three cases are considered: open-loop simulations using real-time satellite precipitation (RT), assimilation of SMOS soil moisture with real-time precipitation (RT + SMOS), and open-loop simulation using reanalyzed precipitation (RE). Since the simulations and the in situ measurements are not directly comparable, only the correlation $(R)$ is shown here. Improvement of the correlation is indicated in bold font.

\begin{tabular}{|c|c|c|c|c|c|c|c|c|c|}
\hline \multirow[t]{2}{*}{ WTD } & \multicolumn{3}{|c|}{ PERSIANN } & \multicolumn{3}{|c|}{ TRMM } & \multicolumn{3}{|c|}{ CMORPH } \\
\hline & RT & $\mathrm{RT}+\mathrm{SMOS}$ & RE & RT & $\mathrm{RT}+\mathrm{SMOS}$ & $\mathrm{RE}$ & RT & $\mathrm{RT}+\mathrm{SMOS}$ & RE \\
\hline$R$ & 0.09 & 0.87 & 0.79 & 0.70 & 0.84 & 0.48 & 0.33 & 0.82 & 0.84 \\
\hline
\end{tabular}

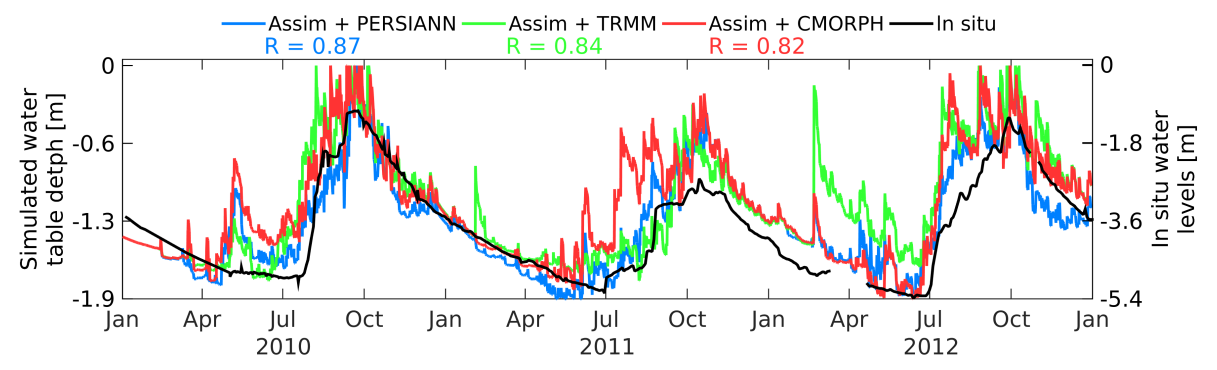

Figure 7. Simulations of the water table depth at the Nalohou station (in situ measurements in black) using RT precipitation for after SMOS assimilation (in colors). Correlations are also indicated in the figure.

depth by $17 \%$ (TRMM) up to $56 \%$ (PERSIANN), and at $80 \mathrm{~cm}$, by $12 \%$ (TRMM) up to $47 \%$ (PERSIANN). The biases are even lower than with PERSIANN and TRMM reanalyzed products. This shows that the assimilation and the model are able to propagate the information from the $5 \mathrm{~cm}$ layer to the deeper layers of the soil. The largest improvements are naturally obtained when the PERSIANN and the CMORPH products are used as precipitation forcing since there are the ones bringing the most extra water in the model. This proves that assimilation can correct for this additional amount of water. Moreover, the open-loop simulations show unrealistic soil saturation at the $5 \mathrm{~cm}$ layer during the rain season (soil moisture value is equal to porosity, see Fig. 6), which is also the case at deeper layers later in the season (not shown here). This saturation issue is improved after assimilation, but can still happen.

Assimilation does not correct directly the precipitation: neither for the amount of water nor for the time of the event itself. So the volume of water given to the model remains the same and the peaks in the soil moisture simulations cannot be corrected until a SMOS observation becomes available, and only the drying phase can then be modified.

The impact of the assimilation on the evapotranspiration variable has also been studied but not shown here. The changes in evapotranspiration were very small after the assimilation using the real-time precipitation products: it was overestimated before $(+3$ to $+9 \%)$ and was still after (around $+9 \%$ ) for all products.

\subsection{Impact on the water table depth simulations}

Figure 7 shows the simulations of the WTD after SMOS assimilation. Only the correlation is calculated because of the scale difference.

There is a clear benefit from the SMOS soil assimilation even at deeper layers than the ones used for the assimilation directly. The peaks in the period from April to June are strongly reduced and the temporal behavior is in line with the in situ time evolution. The correlation scores are also a good indicator of the improvement brought by the assimilation and it is improved for all the precipitation products. Compared to Fig. 3, the seasonal behavior of the water table depth is much more respected with smoother peaks during the dry season. The statistics performances are summarized in Table 3 for all the options: RT precipitation only, SMOS assimilation using RT forcing, and RE precipitation only. After assimilation, the performances are either even better or equivalent compared to RE simulations.

\subsection{Impact on the streamflow simulations}

Finally, Fig. 8 shows the simulations of the streamflow at the outlet of the basin after assimilation. Compared to the open-loop simulations in Fig. 4, improvements can clearly be identified: the rises are smoother, the dry season is more respected, and the time evolution is much more in line with the in situ observations than using RT precipitation alone. Table 4 shows the statistics of the streamflow simulations using the three satellite products.

Except for the TRMM product, all the streamflow statistics are improved by the assimilation, especially the error 
Table 4. Statistics of the simulated streamflow $(Q)$ compared to the in situ measurements at the outlet of the basin for 2010-2012. Three cases are considered: open-loop simulations using real-time satellite precipitation (RT), assimilation of SMOS soil moisture with real-time precipitation (RT + SMOS) and open-loop simulation using reanalyzed precipitation (RE). Improvements are indicated in bold font.

\begin{tabular}{|c|c|c|c|c|c|c|c|c|c|}
\hline \multirow[t]{2}{*}{$Q$} & \multicolumn{3}{|c|}{ PERSIANN } & \multicolumn{3}{|c|}{ TRMM } & \multicolumn{3}{|c|}{ CMORPH } \\
\hline & RT & $\mathrm{RT}+\mathrm{SMOS}$ & RE & RT & $\mathrm{RT}+\mathrm{SMOS}$ & RE & RT & $\mathrm{RT}+\mathrm{SMOS}$ & RE \\
\hline$R$ & 0.39 & 0.78 & 0.78 & 0.86 & 0.81 & 0.82 & 0.64 & 0.81 & 0.88 \\
\hline bias & 147.2 & 4.5 & -15.6 & 44.4 & 40.9 & -15.5 & 214.6 & 47.8 & -19.9 \\
\hline sdd & 292.2 & 111.2 & 112.2 & 120.3 & 131.4 & 105.2 & 356.6 & 134.2 & 85.8 \\
\hline RMSE & 327.2 & 111.3 & 113.3 & 128.3 & 137.6 & 106.3 & 416.2 & 142.5 & 88.0 \\
\hline Nash & -2.45 & 0.60 & 0.59 & 0.47 & 0.39 & 0.64 & -4.59 & 0.35 & 0.75 \\
\hline
\end{tabular}
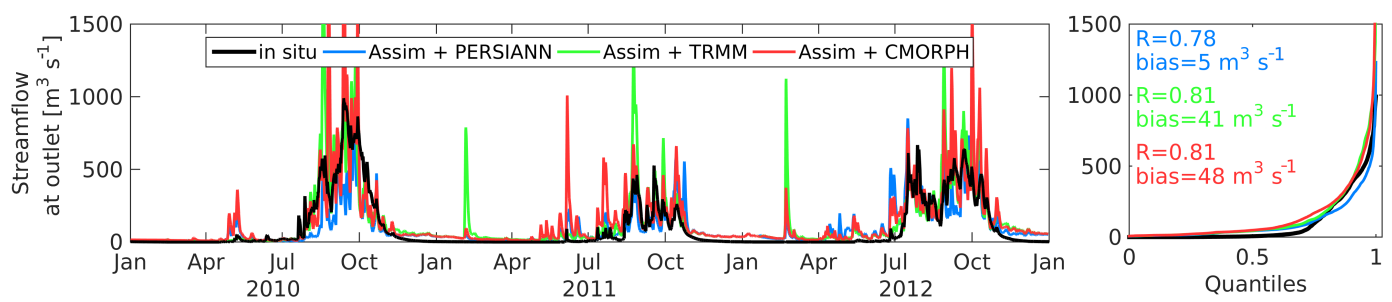

Figure 8. Simulations of the streamflow at the outlet after SMOS soil moisture assimilation with real-time precipitation forcing (indicated in colors for PERSIANN, TRMM and CMORPH) compared to in situ measurements (black line).

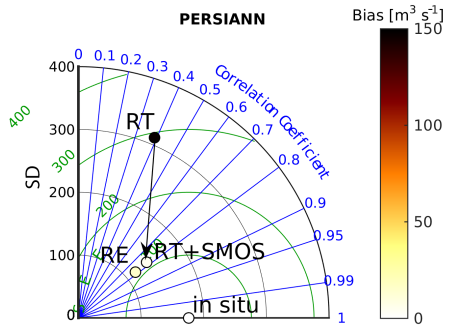

SD

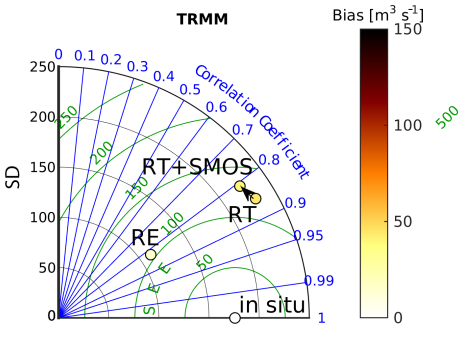

SD

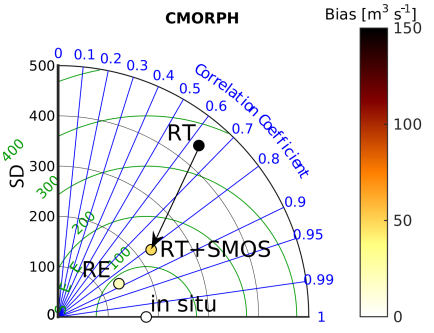

SD

Figure 9. Taylor diagrams of the streamflow performances for the three rainfall products (PERSIANN on the left, TRMM in the middle, CMORPH on the right) using their real-time version only (RT), their reanalyzed version (RE), and the RT version after SMOS assimilation $(\mathrm{RT}+\mathrm{SMOS})$. The arrow shows the changes in the statistics before and after SMOS assimilation.

(divided by 3), and the Nash coefficient (from negative to positive). Even if the reanalyzed precipitation produce better performances, the improvement using SMOS assimilation with RT precipitation is important. The TRMM case is different from the other two products since the RT version already gives fair performances, and the assimilation degrades these performances a little bit, whereas the reanalyzed version slightly improves them.

Another representation of these statistics is the Taylor diagram in Fig. 9. It shows in a more graphical way the improvement brought by the assimilation of SMOS soil moisture products. The in situ circle on the bottom axis represents the point to be reached by the simulations, which would mean that there is a temporal correlation of 1 (blue radial axis on the right), the standard deviation is the same as the in situ (temporal variability, gray circular axis), the standard deviation of the difference between the simulations and the in situ is null (green semi-circular axis) and the bias would also be null (point circle filled with colors indicated by the color bar on the right for the absolute value of the bias). In other words, the closer to the in situ point, the better.

The arrows on the diagram show the impact of the assimilation on the statistics using RT precipitation. For TRMM, the after-assimilation point is not much closer indicating no clear evidence of improvement from the assimilation. As mentioned before, the TRMM precipitation product already gave the proper amount of water, so SMOS assimilation cannot improve it very much. However, simulations using PERSIANN and CMORPH products are greatly improved by the assimilation attested by the long arrows ending much closer to the RE and in situ points. 


\section{Conclusions}

Precipitation forcing is generally the main driver in hydrological models and it is generally not simple nor immediate to collect and distribute in situ measurements in sufficient number and of quality. If in situ precipitation can be used for model calibration, real-time or quasi-real-time applications require forcing and observations quickly in order to react accordingly, such as in the case of a flooding event. Accurate rainfall products from satellite observations are usually reanalyzed data sets available 2 to 3 months after. Although realtime precipitation products are expected to be biased, they are available a few hours to a couple of days after the observations. Three satellite rainfall products have been tested: PERSIANN, TRMM and CMORPH.

The study shows the benefit of the assimilation of the SMOS soil moisture products on three hydrological variables: the soil moisture, the water table depth and the streamflow, which are key variables in the hydrological processes.

By assimilating SMOS soil moisture, the first impacted variables were naturally the soil moisture of the different soil layers of the model. Here, we have showed that, even using a very simplistic methodology of assimilation, the bias in the simulated soil moisture has decreased significantly after the assimilation using the real-time precipitation product. At deeper ground, the simulations of the water table depth showed a much better correlation after the assimilation when compared to in situ measurements (from 0.09-0.70 to 0.820.87). These scores were either higher or equivalent to those from the reanalyzed rainfall products. This positive impact of the assimilation on these hydrological variables can lead to a better simulation and management of the actual ground water resources.

The inaccurate amount of water brought by the real-time rainfall products also has a substantial impact on the streamflow. The extra water can saturate the soil faster, thus increase the runoff and the subsurface lateral flow, and be finally intercepted by the water channel. This whole sequence of processes is also positively impacted by the soil moisture assimilation. The streamflow at the outlet of the basin has been much improved for the PERSIANN and CMORPH rainfall products with errors divided by a factor 3 and a Nash coefficient going from negative to positive (TRMM real-time product was already fairly good compared to the other realtime products). After assimilation, the performances were either slightly lower or equivalent to those using the reanalyzed products. Again, this positive impact of the assimilation can lead to a better simulation and management of extreme events such as floods during the monsoon period in this case.

This work shows the possibility to implement a near-realtime hydrologic framework for real-time application wherever it is possible to obtain a proper calibration of the hydrological model beforehand, which is one limitation of this method but this can be overcome by using reanalyzed satel- lite precipitation. Optionally, the real-time rainfall products could be directly corrected using SMOS observations and following current methodologies (Crow et al., 2011; Pellarin et al., 2013; Brocca et al., 2014; Wanders et al., 2015). Another limitation comes from the choice of the assimilation method. Optimal interpolation relies on assumptions about the error covariances of the model and the observations. In this study, these two matrices have been over-simplified. By implementing ensemble technics, these assumptions could be avoided and the impact of the soil moisture assimilation on the other hydrological variables would be enhanced.

Acknowledgements. The authors would like to first thank the Direction Générale de l'Eau du Bénin for the streamflow measurements at the two sub-catchments (Beterou and Cote 238), and the Centre National d'Etudes Spatiales (CNES) TOSCA program for funding this project. The authors would also like to acknowledge the Global Modeling and Assimilation Office (GMAO) and the GES DISC for the dissemination of MERRA data, NOAA and NASA for the dissemination of the precipitation products (PERSIANN, TRMM and CMORPH), the AMMA-CATCH team for providing the in situ measurements, and the ALMIP-2 team for the first DHSVM calibration set. The AMMA-CATCH regional observing system was set up thanks to an incentive funding of the French Ministry of Research that allowed pooling together various pre-existing small-scale observing setups. The continuity and long-term perennity of the measurements have been made possible by uninterrupted IRD funding since 1990 and by continuous CNRS-INSU funding since 2005.

Edited by: F. Fenicia

\section{References}

Bitew, M. M. and Gebremichael, M.: Assessment of satellite rainfall products for streamflow simulation in medium watersheds of the Ethiopian highlands, Hydrol. Earth Syst. Sci., 15, 1147-1155, doi:10.5194/hess-15-1147-2011, 2011.

Brocca, L., Melone, F., Moramarco, T., Wagner, W., Naeimi, V., Bartalis, Z., and Hasenauer, S.: Improving runoff prediction through the assimilation of the ASCAT soil moisture product, Hydrol. Earth Syst. Sci., 14, 1881-1893, doi:10.5194/hess-141881-2010, 2010.

Brocca, L., Moramarco, T., Melone, F., Wagner, W., Hasenauer, S., and Hahn, S.: Assimilation of surface and root-zone ASCAT soil moisture products into rainfall-runoff modeling, IEEE T. Geosci. Remote, 50, 2542-2555, 2012.

Brocca, L., Ciabatta, L., Massari, C., Moramarco, T., Hahn, S., Hasenauer, S., Kidd, R., Dorigo, W., Wagner, W., and Levizzani, V.: Soil as a natural rain gauge: estimating global rainfall from satellite soil moisture data, J. Geophys. Res., 119, 5128-5141, 2014.

Casse, C., Gosset, M., Peugeot, C., Pedinotti, V., Boone, A., Tanimoun, B., and Decharme, B.: Potential of satellite rainfall products to predict NIger River flood events in Niamey, Atmos. Res., 163, 162-176, 2015. 
Chakrabarti, S., Bongiovanni, T., Judge, J., Zotarelli, L., and Bayer, C.: Assimilation of SMOS soil moisture for quantifying drought impacts on crop yield in agricultural regions, IEEE J. Select. Top. Appl. Earth Obs. Rem. S., 7, 3867-3879, 2014.

Crow, W., van den Berg, M., Huffman, G., and Pellarin, T.: Correcting rainfall using satellite-based surface soil moisture retrievals: the Soil Moisture Analysis Rainfall Tool (SMART), Water Resour. Res., 47, W08521, doi:10.1029/2011WR010576, 2011.

Cuartas, L., Tomasella, J., Nobre, A., Nobre, C., Hodnett, M., Waterloo, M., de Oliveira, S., de Cassia von Randow, R., Trancoso, R., and Ferreira, M.: Distributed hydrological modeling of a micro-scale rainforest watershed in Amazonia: model evaluation and advances in calibration using the new HAND terrain model, J. Hydrol., 462-463, 15-27, 2012.

Cuo, L., Giambelluca, T., Ziegler, A., and Nullet, M.: Use of the distributed hydrology soil vegetation model to study road effects on hydrological processes in Pang Khum Experimental Watershed, northern Thailand, Forest Ecol. Manage., 224, 81-94, 2006.

De Lannoy, G., Reichle, R., Houser, P., Arsenault, K., Verhoest, N., and Pauwels, V.: Satellite-scale snow water equivalent assimilation into a high-resolution land surface model, J. Hydrometeorol., 11, 352-369, 2010.

Draper, C., Reichle, R., De Lannoy, G., and Liu, Q.: Assimilation of passive and active microwave soil moisture retrievals, Geophys. Res. Lett., 39, L04401, doi:10.1029/2011GL050655, 2012.

Du, E., Link, T., Gravelle, J., and Hubbart, J.: Validation and sensitivity test of the distributed hydrology soil vegetation model (DHSVM) in a forested mountain watershed, Hydrol. Process., 28, 6196-6210, 2014.

Gascon, T., Vischel, T., Lebel, T., Quantin, G., Pellarin, T., Quatela, V., Leroux, D., and Galle, S.: Influence of rainfall space-time variability over the Ouémé basin in Benin, P. Int. Assoc. Hydrolog. Sci., 368, 102-107, 2015.

Gaspari, G. and Cohn, S.: Construction of correlation functions in two and three dimensions, Q. J. Roy. Meteorol. Soc., 125, 723$757,1999$.

Gosset, M., Viarre, J., Quantin, G., and Alcoba, M.: Evaluation of several rainfall products used for hydrological applications over West Africa using two high-resolution gauge networks, Q. J. Roy. Meteorol. Soc., 139, 923-940, 2013.

Han, E., Merwade, V., and Heathman, G.: Implementation of surface soil moisture data assimilation with watershed scale distributed hydrological model, J. Hydrol., 416, 98-117, 2012.

Hollmann, R., Merchant, C., Saunders, R., Downy, C., Buchwitz, M., Cazenave, A., Chiuveco, E., Defourny, P., de Leeuw, G., Forsberg, R., Holzer-Popp, T., Paul, F., Sandven, S., Sathyendranath, S., van Roozendael, M., and Wagner, W.: The ESA climate change initiative satellite data records for essential climate variables, B. Am. Meteorol. Soc., 94, 1541-1552, 2013.

Hsu, K., Gao, X., and Sorooshian, S.: Precipitation estimation from remotely sensed information using artificial neural networks, J. Appl. Meteorol., 36, 1176-1190, 1997.

Huffman, G., Adler, R., Bolvin, D., Gu, G., Nelkin, E., Bowman, K., Hong, Y., Stocker, E., and Wolff, D.: The TRMM multi-satellite precipitation analysis: quasi-global, multi-year, combined-sensor precipitation estimates at fine scale, J. Hydrometeorol., 8, 38-55, 2007.

Jacquette, E., Al Bitar, A., Mialon, A., Kerr, Y., Quesney, A., Cabot, F., and Richaume, P.: SMOS CATDS level 3 global products over land, Proceedings of SPIE-The International Society for Optical Engineering, Remote Sensing for Agriculture, Ecosystems, and Hydrology XII, vol. 7824, article number 78240K, SPIE conference, 20-22 September 2010, Toulouse, France, 2010.

Joyce, R., Janowiak, J., Arkin, P., and Xie, P.: CMORPH: a method that produces global precipitation estimates from passive microwave and infrared data at high spatial and temporal resolution, J. Hydrometeorol., 5, 487-503, 2004.

Kerr, Y., Waldteufel, P., Richaume, P., Wigneron, J.-P., Ferrazzoli, P., Mahmoodi, A., Bitar, A. A., Cabot, F., Gruhier, C., Juglea, S., Leroux, D., Mialon, A., and Delwart, S.: The SMOS Soil Moisture Retrieval Algorithm, IEEE T. Geosci. Remote, 50, 13841403, 2012.

Kerr, Y., Waldteufel, P., Richaume, P., Daveport, I., Ferrazzoli, P., and Wigneron, J.-P.: SMOS Level 2 Processor Soil Moisture ATBD, Tech. Rep. SO-TN-ESL-SM-GS-0001, SM-ESL, CBSA, available at: http://www.cesbio.ups-tlse.fr/SMOS_blog/ ?page_id=815 (last access: July 2016), 2015.

Khan, S. I., Adhikari, P., Hong, Y., Vergara, H., Adler, R., Policelli, F., Irwin, D., Korme, T., and Okello, L.: Hydroclimatology of Lake Victoria region using hydrologic model and satellite remote sensing data, Hydrol. Earth Syst. Sci., 15, 107-117, doi:10.5194/hess-15-107-2011, 2011.

Kumar, S., Peters-Lidard, C., Mocko, D., Reichle, D., Liu, Y., Arsenault, K., Xia, Y., Ek, M., Riggs, G., Livneh, B., and Cosh, M.: Assimilation of remotely sensed soil moisture and snow depth retrievals for drought estimation, J. Hydrometeorol., 15, 24462469, 2014.

Lebel, T., Cappelaere, B., Galle, S., Hanan, N., Kergoat, L., Levis, S., Vieux, B., Descroix, L., Gosset, M., Mougin, E., Peugeot, C., and Seguis, L.: AMMA-CATCH studies in the Sahelian region of West-Africa: an overview, J. Hydrol., 375, 3-13, 2009.

Li, X.-H., Zhang, Q., and Xu, C.-Y.: Suitability of the TRMM satellite rainfalls in driving a distributed hydrological model for water balance computations in Xinjiang catchment, Poyang lake basin, J. Hydrol., 426-427, 28-38, 2012.

Lievens, H., Tomer, S., Al Bitar, A., de Lannoy, G., Drusch, M., Dumedah, G., Hendricks Franssen, H., Kerr, Y., Martens, B., Pan, M., Roundy, J., Vereecken, H., Walker, J., Wood, E., Verhoest, N., and Pauwels, V.: SMOS soil moisture assimilation for improved hydrologic simulation in the Murray Darling basin, Australia, Remote Sens. Environ., 168, 146-162, 2015.

Liu, Y., Dorigo, W., Parinussa, R., de Jeu, R., Wagner, W., McCabe, M., Evans, J., and van Dijk, A.: Trend-preserving blending of passive and active microwave soil moisture retrievals, Remote Sens. Environ., 123, 280-297, 2012.

Liu, Y. Y., Parinussa, R. M., Dorigo, W. A., De Jeu, R. A. M., Wagner, W., van Dijk, A. I. J. M., McCabe, M. F., and Evans, J. P.: Developing an improved soil moisture dataset by blending passive and active microwave satellite-based retrievals, Hydrol. Earth Syst. Sci., 15, 425-436, doi:10.5194/hess-15-425-2011, 2011.

Louvet, S., Pellarin, T., al Bitar, A., Cappelaere, B., Galle, S., Grippa, M., Gruhier, C., Kerr, Y., Lebel, T., Mialon, A., Mougin, E., Quantin, G., Richaume, P., and de Rosnay, P.: SMOS soil moisture product evaluation over West-Africa from local to regional scale, Remote Sens. Environ., 156, 383-394, 2015.

Nash, J. and Sutcliffe, J.: River flow forecasting through conceptual models 1, a discussion of principles, J. Hydrol., 10, 282-290, 1970. 
Parrens, M., Mahfouf, J.-F., Barbu, A. L., and Calvet, J.-C.: Assimilation of surface soil moisture into a multilayer soil model: design and evaluation at local scale, Hydrol. Earth Syst. Sci., 18, 673-689, doi:10.5194/hess-18-673-2014, 2014.

Pauwels, V., Hoeben, R., Verhoest, N., and Troch, F. D.: The importance of the spatial patterns of remotely sensed soil moisture in the improvement of discharge predictions for small-scale basins through data assimilation, J. Hydrol., 251, 88-102, 2001.

Pauwels, V., Hoeben, R., Verhoest, N., Troch, F. D., and Troch, P.: Improvement of TOPLATS-based discharge predictions through assimilation of ERS-based remotely sensed soil moisture values, Hydrol. Process., 16, 995-1013, 2002.

Pellarin, T., Louvet, S., Gruhier, C., Quantin, G., and Legout, C.: A simple and effective method for correcting soil moisture and precipitation estimates using AMSR-E measurements, Remote Sens. Environ., 136, 28-36, 2013.

Reichle, R. and Koster, R.: Assessing the impact of horizontal error correlations in background fields on soil moisture estimation, J. Hydrometeorol., 4, 1229-1242, 2003.

Renzullo, L., van Dijk, A., Perraud, J.-M., Collins, D., Hendreson, B., Jin, H., Smith, A., and McJannet, D.: Continental satellite soil moisture data assimilation improves root-zone moisture analysis for water resources assessment, J. Hydrol., 519, 2747-2762, 2014.

Ridler, M.-E., Madsen, H., Stisen, S., Bircher, S., and Fensholt, R.: Assimilation of SMOS-derived soil moisture in a fully integrated hydrological and soil-vegetation-atmosphere transfer model in Western Denmark, Water Resour. Res., 50, 8962-8981, 2014.

Rienecker, M., Suarez, M., Gelaro, R., Todling, R., Bacmeister, J., Liu, E., Bosilovich, M., Schubert, S., Takacs, L., Kim, G.-K., Bloom, S., Chen, J., Collins, D., Conaty, A., Da Silva, A., Gu, W., Joiner, J., Koster, R., Lucchesi, R., Molod, A., Owens, T., Pawson, S., Pegion, P., Redder, C., Reichle, R., Robertson, F., Ruddick, A., Sienkiewicz, M., and Woollen, J.: MERRA: NASA's Modern-Era Retrospective Analysis for Research and Applications, J. Climate, 24, 3624-3648, 2011.

Sahoo, A., De Lannoy, G., Reichle, R., and Houser, P.: Assimilation and downscaling of satellite observed soil moisture over the Little River experimental watershed in Georgia, USA, Adv. Water Resour., 52, 19-33, 2013.

Seguis, L., Kamagate, B., Favreau, G., Descloitres, M., Seidel, J., Galle, S., Peugeot, C., Gosset, M., Le Barbe, L., Malinur, F., Van Exter, S., Arjounin, M., Boubkraoui, S., and Wubda, M.: Origins of streamflow in a crystalline basement catchment in a sub-humid Sudanian zone: The Donga basin (Benin, West Africa) Inter-annual variability of water budget, J. Hydrol., 402, $1-13,2011$.
Sorooshian, S., Hsu, K., Gao, X., Gupta, H., Imam, B., and Braithwaite, D.: Evaluation of PERSIANN system satellite-based estimates of tropical rainfall, B. Am. Meteorol. Soc., 81, 2035-2046, 2000.

Thiemig, V., Rojas, R., Zambrano-Bigiarini, M., Levizzani, V., and Roo, A. D.: Validation of satellite-based precipitation products over sparsely gauged African river basins, J. Hydrometeorol., 13, 1760-1783, 2012.

Vischel, T. and Lebel, T.: Assessing the water balance in the Sahel: impact of small scale rainfall variability on runoff. Part 2: idealized modeling of runoff sensitivity, J. Hydrol., 333, 340-355, 2007.

Vischel, T., Quantin, G., Lebel, T., Viarre, J., Gosset, M., Cazenave, F., and Panthou, G.: Generation of high-resolution rain fields in West Africa: evaluation of dynamics interpolation methods, J. Hydrometeorol., 12, 1465-1482, 2011.

Wagner, W., Dorigo, W., de Jeu, R., Fernandez, D., Benveniste, J., Haas, E., and Ertl, M.: Fusion of active and passive microwave observations to create an Essential Climate Variable data record on soil moisture, ISPRS Annals of the Photogrammetry, Remote Sensing and Spatial Information Sciences (ISPRS Annals), I-7, XXII ISPRS Congress, Melbourne, Australia, 315-321, 2012.

Wanders, N., Karssenberg, D., de Roo, A., de Jong, S. M., and Bierkens, M. F. P.: The suitability of remotely sensed soil moisture for improving operational flood forecasting, Hydrol. Earth Syst. Sci., 18, 2343-2357, doi:10.5194/hess-18-23432014, 2014.

Wanders, N., Pan, M., and Wood, E.: Correction of real-time satellite precipitation with multi-sensor satellite observations of land surface variables, Remote Sens. Environ., 160, 206-221, 2015.

Ward, E., Buytaert, W., Peaver, L., and Wheater, H.: Evaluation of precipitation products over complex mountainous terrain: a water resources perspective, Adv. Water Resour., 34, 1222-1231, 2011.

Whitaker, A., Alila, Y., Beckers, J., and Toews, D.: Application of the Distributed Hydrology Soil Vegetation Model to Redfish Creek, British Columbia: model evaluation using internal catchment data, Hydrol. Process., 17, 199-224, 2003.

Wigmosta, M., Vail, L., and Lettemaier, D.: A distributed hydrology-vegetation model for complex terrain, Water Resour. Res., 30, 1665-1679, 1994.

Yilmaz, M. and Crow, W.: The optimality of potential rescaling approches in land data assimilation, J. Hydrometeorol., 14, 650660, 2013. 